\title{
Perbandingan antara Sevofluran dan Propofol Menggunakan Total Intravenous Anesthesia Target Controlled Infusion terhadap Waktu Pulih Sadar dan Pemulangan Pasien pada Ekstirpasi Fibroadenoma Payudara
}

\author{
Arvianto, ${ }^{1}$ Ezra Oktaliansah, ${ }^{2}$ Eri Surahman ${ }^{2}$ \\ ${ }^{1}$ Kasubdep Bedah dan Anestesi Rumah Sakit TK.II Kesdam Iskandar Muda, \\ ${ }^{2}$ Departemen Anestesiologi dan Terapi Intensif \\ Fakultas Kedokteran Universitas Padjadjaran/Rumah Sakit Dr. Hasan Sadikin Bandung
}

\begin{abstract}
Abstrak
Penggunaan total intravenous anesthesia (TIVA) dengan propofol terus meningkat karena mudah untuk dikendalikan, onset cepat, durasi singkat, efek samping minimal, serta pemulihan psikomotor dan kognitif lebih cepat. Penelitian ini bertujuan mengetahui perbandingan waktu pulih sadar dan pemulangan pasien antara teknik anestesi sevofluran dan TIVA TCI propofol. Penelitian ini dilakukan secara acak terkontrol buta tunggal terhadap 36 orang pasien bedah rawat jalan, wanita usia 18-65 tahun dengan status fisik American Society of Anesthesiologists (ASA) kelas I-II yang menjalani operasi biopsi ekstirpasi fibroadenoma payudara satu sisi di Rumah Sakit Dr. Hasan Sadikin Bandung periode Agustus-November 2015. Sampel dikelompokkan secara random menjadi kelompok sevofluran dan TCI. Kelompok sevofluran mendapatkan anestesi inhalasi sevofluran dan kelompok TCI mendapatkan anestesi TCI propofol dengan metode Schnider Effect Concentration (ec). Waktu pulih sadar dan pemulangan pasien dikumpulkan dan dianalisis menggunakan uji-t, uji Mann-Whitney, dan chi-kuadrat dengan tingkat kepercayaan 95\%. Hasil penelitian menunjukkan perbandingan waktu pulih sadar pada kelompok sevofluran 7,429 $\pm 0,763$ menit, sedangkan kelompok TCI 9,356 $\pm 2,331$ menit. Simpulan penelitian adalah teknik anestesi sevofluran memberikan waktu pulih sadar yang lebih cepat dan TIVA TCI propofol memberikan waktu pemulangan pasien yang lebih cepat.
\end{abstract}

Kata kunci: Fibroadenoma payudara, sevofluran, TIVA TCI propofol, waktu pulih sadar, waktu pemulangan pasien

\section{Comparison of Emergence Time and Discharge Time between Sevoflurane and Propofol Using Total Intravenous Anesthesia with Target Controlled Infusion in Patients Underwent Extirpation of Breast Fibroadenoma}

\begin{abstract}
Total intravenous anesthesia (TIVA) with propofol is increasingly used, because it is easy to control, has rapid onset, short duration, minimal adverse effects, and rapid recovery of the psychomotor and cognitive functions. This study was conducted to compare the emergence and discharge time between patients receiving sevoflurane and propofol with TCI. A single blind randomized controlled clinical trial was conducted on 36 female patients aged 18-65 years with American Society of Anesthesiologists (ASA) physical status I-II, who underwent breast fibroadenoma extirpation biopsy at the outpatient surgical unit in Dr. Hasan Sadikin General Hospital Bandung. The subjects were randomized and divided into two groups: sevoflurane group receiving inhalation anesthesia with sevoflurane and target controlled infusion (TCI) group receiving propofol TCI Schnider's Effect Concentration (ec). The emergence time and discharge time were recorded for each group and analysis was performed using Mann Whitney test, t-test and chi-square/ Fisher's exact with 95\% confidence interval. This study showed that the emergence time in sevoflurane group and TCI group were $7.429 \pm 0.763$ minutes and $9.356 \pm 2.331$ minutes, respectively. The result showed that sevoflurane provides shorter emergence time while TIVA with TCI propofol provides shorter discharge time.
\end{abstract}

Key words: Breast fibroadenoma, emergence time, patients discharging time TIVA TCI propofol, sevoflurane Korespondensi: Mayor Ckm. Arvianto, dr., SpAn, Kasubdep Bedah dan Anestesi Rumah Sakit TK.II Kesdam Iskandar Muda, Jl. T. Hamzah Bendahara No. 1, Kuta Alam-Banda Aceh, Tlpn. 0651-24712, Mobile 08129912529, Email arvianto_ dr@yahoo.com 


\section{Pendahuluan}

Prosedur pembedahan yang dilakukan pada pasien tanpa kelainan sistemik berat dengan waktu singkat bisa dilakukan dengan prosedur bedah rawat jalan. Pelaksanaan bedah rawat jalan harus memenuhi persyaratan ditinjau dari pertimbangan faktor-faktor pembedahan, kelengkapan sarana pendukung, dan anestesi. Anestesi untuk bedah rawat jalan yang ideal adalah proses induksi anestesi dengan onset dan juga pemulihan yang cepat, nyaman untuk pasien, efek analgesik pascabedah adekuat, serta pengendalian mual-muntah yang baik. ${ }^{1-3}$

Anestesi dengan rumatan agen inhalasi merupakan teknik yang banyak dipilih pada anestesi umum. Teknik anestesi umum dengan rumatan inhalasi memberikan tiga kebutuhan anestesi umum dengan derajat yang bervariasi, yakni efek analgesik, hipnotik-sedatif, dan juga relaksasi otot. Sifat lain adalah efek terhadap hemodinamik yang lebih stabil, tidak mudah terbakar, toksisitas terhadap organ minimal, dan mudah diberikan secara titrasi. ${ }^{4,5}$ Anestesi inhalasi sevofluran telah banyak digunakan oleh ahli anestesi karena rendahnya kelarutan darah-gas dan juga darah-jaringan sehingga pemulihan anestesi lebih cepat. ${ }^{5,6}$

Teknik anestesi umum dapat dilakukan dengan anestesi inhalasi, anestesi intravena, ataupun kombinasi kedua teknik tersebut. Saat memilih teknik dan obat yang akan digunakan dalam anestesi umum perlu dipertimbangkan berbagai hal, antara lain adalah keamanan dan kemudahan dalam melakukan teknik tersebut, kecepatan induksi dan pemulihan, stabilitas hemodinamik, efek samping yang ditimbulkan, serta biaya yang diperlukan. ${ }^{6}$

Teknik yang memakai kombinasi antara anestesi intravena sebagai obat induksi dan anestesi inhalasi sebagai rumatan cukup mudah serta aman digunakan namun terdapat kekurangan yang harus diperhatikan. Waktu pemulihan yang lama atau efek samping yang dapat timbul terutama mual-muntah pascaanestesi memerlukan obat tambahan untuk pencegahannya. ${ }^{7,8}$ Anestesi inhalasi sevofluran merupakan agen anestesi yang cukup ideal untuk operasi bedah rawat jalan dalam hal waktu induksi dan juga pulih sadar yang cepat serta hemodinamik yang tetap stabil selama anestesi. Namun, efek samping mual-muntah, agitasi pasca-anestesi masih mungkin terjadi. Selain itu, sevofluran membutuhkan biaya yang lebih besar bila dibanding dengan obat anestesi inhalasi lain seperti halotan, enfluran, atau isofluran. ${ }^{4,5,6}$

Saat ini telah berkembang pengetahuan mengenai teknik dan obat anestesi intravena untuk induksi yang digunakan juga sebagai rumatan anestesi untuk menggantikan anestesi inhalasi. Teknik anestesi yang menggunakan jalur intravena sebagai jalan masuk obat untuk induksi dan rumatan disebut total intravenous anesthesia (TIVA). ${ }^{9}$

Teknik anestesi intravena total bertujuan mencapai kondisi anestesi yang seimbang melalui penyuntikan beberapa golongan obat. Opioid, hipnotik-sedatif, dan pelumpuh otot merupakan golongan obat yang digunakan sebagai kombinasi untuk melakukan teknik anestesi dengan TIVA. Namun, pemilihan obat tersebut perlu disesuaikan dengan kondisi pasien, jenis operasi, dan lama operasi. ${ }^{9}$

Setelah ditemukan obat anestesi intravena yang lebih poten dengan mula kerja yang cepat, lama kerja singkat, serta efek samping rendah, saat ini teknik anestesi dengan TIVA semakin banyak digunakan terutama pada prosedur bedah rawat jalan. Propofol merupakan obat hipnotik-sedatif untuk anestesi umum yang mulai diperkenalkan pada tahun 1985 . Farmakokinetik dan farmakodinamik obat ini memenuhi hampir semua faktor agar menjadi obat anestesi yang ideal. Saat ini propofol menjadi obat hipnotik-sedatif yang paling populer dalam anestesi umum untuk hampir semua jenis operasi. ${ }^{10}$ Mula kerja yang cepat, konsentrasidalamdarahyangcepatdieliminasi, dan waktu pemulihan anestesi yang singkat menjadi kelebihan propofol dibanding dengan obat-obat hipnotik-sedatif intravena lainnya. Penelitian sebelumnya telah membuktikan bahwa pada pasien yang diberikan propofol memiliki waktu pulih terhadap fungsi kognitif dan psikomotor lebih cepat dibanding dengan obat anestesi yang lain. ${ }^{10}$ Propofol juga tidak menimbulkan efek samping mual-muntah, 
sebaliknya mempunyai efek antimual-muntah yang kuat. ${ }^{11}$ Efek yang sering timbul pada penyuntikan propofol adalah hipotensi akibat depresi sistem kardiovaskular karena propofol menurunkan tahanan pembuluh darah perifer dan kontraktilitas jantung. ${ }^{12}$

Sejak 10 tahun terakhir telah dikembangkan teknologi syringe pump khusus yang digunakan dalam teknik TIVA. Teknologi ini disebut target controlled infusion (TCI). ${ }^{11}$ Penggunaan teknologi TCI pada TIVA memberikan berbagai keuntungan, antara lain waktu induksi anestesi yang lebih cepat, kebutuhan propofol lebih sedikit, dan kedalaman anestesi lebih adekuat. Teknolgi TCI saat ini belum banyak digunakan oleh ahli anestesi karena pemahaman yang kurang dan ketersediaan alat masih terbatas. ${ }^{11}$

Perkembangan teknologi TCI membuat ahli anestesi dapat menentukan target konsentrasi dalam organ yang spesifik, yaitu konsentrasi dalam plasma (plasma concentration/pc) dan konsentrasi dalam otak (effect concentration/ ec). Pada pasien muda tanpa penyakit penyerta, model Marsh pc lebih sering dipilih karena toleransi hemodinamik dan respirasi lebih baik sehingga kejadian awareness lebih jarang. Namun, pada pasien dengan usia yang lebih tua, model Schnider ec lebih dipilih karena toleransi hemodinamik dan respirasi yang lebih sempit, namun kadang-kadang masih didapatkan kejadian awareness bila digunakan dengan target konsentrasi minimal. ${ }^{13}$

Tindakan operasi untuk massa di payudara yang membutuhkan waktu singkat yang sering dilakukan adalah ekstirpasi fibroadenoma payudara (fibroadenoma mammae/FAM). Pasien dengan diagnosis FAM yang dilakukan biopsi ektirpasi merupakan kandidat untuk dilakukan operasi dalam bedah rawat jalan. ${ }^{14}$ Untuk operasi ini, anestesi umum merupakan teknik yang paling sering dipilih, termasuk di Rumah Sakit Dr. Hasan Sadikin Bandung. Teknik TIVA dengan propofol merupakan salah satu teknik anestesi umum yang sering digunakan pada tindakan ekstirpasi FAM. ${ }^{15}$

Berdasar atas uraian di atas, tujuan penelitian ini adalah membandingkan waktu pulih sadar dan pemulangan pasien antara teknik anestesi sevofluran dan TIVA TCI propofol model Schnider ec pada pasien yang dilakukan ekstirpasi fibroadenoma payudara. Penelitian ini merupakan penelitian ulangan dan modifikasi dari penelitian sebelumnya.

\section{Subjek dan Metode}

Penelitian ini dirancang secara prospektif eksperimental dengan menggunakan uji klinis acak buta tunggal (single blind randomized clinical trial). Penelitian ini dilakukan setelah mendapatkan persetujuan dari Komite Etik Penelitian Kesehatan Fakultas Kedokteran Universitas Padjadjaran/Rumah Sakit Dr.Hasan Sadikin Bandung (RSHS). Populasi adalah wanita yang menderita FAM. Subjek penelitian adalah pasien yang menjalani bedah rawat jalan dengan operasi benjolan payudara yang telah memenuhi kriteria inklusi, yaitu pasien yang menderita FAM unilateral, status fisik American Society of Anesthesiologists (ASA) kelas I-II, dan usia 18-65 tahun. Pasien telah diberikan penjelasan dan menyetujui mengenai penelitian dan kesediaan ikut serta dalam penelitian (informed consent). Kriteria eksklusi adalah pasien memiliki kontraindikasi obat-obatan yang digunakan dalam penelitian, pasien mendapatkan obat sedasi sebelum operasi, body mass index (BMI) $>35 \mathrm{~kg} / \mathrm{m}^{2}$, dan jalan napas sulit. Kriteria pengeluaran adalah operasi lebih dari 2 jam.

Pengambilan sampel penelitian dilakukan dengan teknik consecutive sampling dan subjek dialokasikan ke dalam salah satu kelompok mempergunakan blok permutasi. Penentuan besar sampel telah disesuaikan dengan tujuan penelitian dan juga tipe data pada penelitian. Penentuan besar sampel ditentukan berdasar atas rumus untuk menguji perbedaan dua rata-rata dengan taraf kepercayaan 95\% dan kekuatan 90\%.Berdasar atas rumus tersebut didapatkan jumlah sampel minimal untuk tiap kelompok adalah 18 orang sehingga total sampel adalah 36 orang.

Pasien dipuasakan selama 6 jam sebelum pembedahan. Saat pasien berada di ruang persiapan, pasien dipasang infus di tangan yang berlawanan dengan payudara yang akan dilakukan operasi, kemudian diberikan cairan 
Ringer laktat sebanyak $10 \mathrm{~mL} / \mathrm{kgBB}$ untuk mengganti kehilangan cairan selama puasa. Pasien kemudian dimasukkan ke dalam kamar operasi dan dihubungkan dengan alat monitor. Data tekanan darah sistol dan diastol serta laju nadi awal dicatat. Untuk oksigenasi, pasien diberikan oksigen melalui kanul nasal $3 \mathrm{~L} /$ menit.

Pada kelompok anestesi sevofluran, induksi dilakukan dengan fentanil $2 \mu \mathrm{g} / \mathrm{kgBB}$, propofol $2 \mathrm{mg} / \mathrm{kgBB}$, inhalasi sevofluran, kemudian dilakukan pemasangan laryngeal mask airway (LMA) dilanjutkan rumatan anestesi volatil sevofluran 2 vol\% dan gas $\mathrm{N}_{2} \mathrm{O}: \mathrm{O}_{2}$ dalam perbandingan 50\%:50\%. Untuk kelompok TIVA TCI propofol, induksi dilakukan dengan fentanil $2 \mu \mathrm{g} / \mathrm{kgBB}$, propofol $3 \mu \mathrm{g} / \mathrm{mL}$ melalui intravena dengan menggunakan alat TCI yang sudah dimasukkan data pasien, dilanjutkan dengan propofol intravena melalui alat TCI. Operasi dapat dimulai apabila kedalaman anestesi sudah tercapai dengan pedoman nilai bispectral index scoring (BIS) 40-60 dan nilai patient responsse to surgical stimulation (PRST) $0-3$. Pada penelitian ini semua data numerik diuji menggunakan uji-t tidak berpasangan apabila data berdistribusi normal. Analisis selanjutnya menggunakan uji nonparametrik Mann Whitney apabila data tidak berdistribusi normal, dengan derajat kepercayaan 95\% hipotesis satu arah dengan hasil signifikan bila nilai $\mathrm{p}<0,05$ dan sangat signifikan bila nilai $\mathrm{p}<0,01$.

Untuk mendapatkan efek analgesi selama operasi, di awal induksi diberikan fentanil 2 $\mu \mathrm{g} / \mathrm{kgBB}$. Bila anestesi sudah mencapai 30 menit namun operasi belum selesai, peneliti dapat memberikan tambahan fentanil $1 \mu \mathrm{g} /$ kgBB agar efek analgesik tetap adekuat karena efek optimal fentanil sebagai efek analgesik 20-30 menit setelah penyuntikan awal. Hal ini dapat ditunjukkan dengan nilai PRST pada kedua kelompok yang terkontrol 0-3 yang menandakan efek analgesik adekuat selama operasi.

Selain penilaian secara klinis, kedalaman anestesi dipantau menggunakan alat bispectral index scoring (BIS) dengan target nilai 40$60 .{ }^{17}$ Waktu pulih sadar pada penelitian ini ditentukan sejak waktu mulai obat anestesi dihentikan hingga pasien sadar yang ditandai dengan pasien membuka mata spontan atau memberikan respons membuka mata terhadap rangsangan verbal.,18 Pasien dipantau di ruang pemulihan dan diobservasi setiap 30 menit dengan menggunakan postanesthesia discharge scoring system (PADSS). Waktu pemulangan ditentukan saat skor PADSS mencapai nilai $\geq 9$. 3,18

\section{Hasil}

Uji statistika terhadap karakteristik umum dilakukan dengan uji-t tidak berpasangan pada data berdistribusi normal, serta alternatif ujiMann Whitney pada data tidak berdistribusi normal. Karakteristikumum seluruh kelompok penelitian didapatkan perbedaan yang tidak signifikan atau tidak bermakna secara statistik ( $p>0,05$; Tabel 1).

Nilai p pada kategori data numerik dihitung berdasar atas uji-t tidak berpasangan karena data tersebut berdistribusi normal, pada variabel waktu pulih sadar diperoleh waktu pulih sadar kelompok sevofluran lebih cepat dibanding dengan kelompok TCI propofol, perbedaan rata-rata yang signifikan antara kelompok sevofluran dan TCI $(p<0,05$; Tabel 2).

Uji data numerik variabel postanesthesia discharge scoring system (PADSS) dihitung berdasar atas uji-t tidak berpasangan karena data tersebut berdistribusi normal, didapatkan tidak terdapat perbedaan signifikan antara kelompok sevofluran dan TCI $(p>0,05)$. Pada variabel waktu pemulangan, data numerik diuji berdasar atas uji-t tidak berpasangan karena data tersebut berdistribusi normal, dan didapatkan pada kelompok TCI propofol lebih cepat dibanding dengan kelompok sevofluran dengan perbedaan yang sangat signifikan atau sangat bermakna secara statistika $(\mathrm{p}<0,01$; Tabel 3).

Data kejadian efek samping menunjukkan bahwa selama di ruang pemulihan pasien pada kelompok sevofluran lebih banyak mengalami keluhan mual, pusing, dan nyeri dibanding dengan kelompok TCI propofol (Tabel 4). 
Tabel 1 Karakteristik Umum Subjek Penelitian

\begin{tabular}{|c|c|c|c|}
\hline \multirow{3}{*}{ Variabel } & \multicolumn{2}{|c|}{ Kelompok } & \multirow{3}{*}{ Nilai p*) } \\
\hline & Sevofluran & TCI & \\
\hline & $(n=18)$ & $(n=18)$ & \\
\hline Usia (tahun) & & & 0,696 \\
\hline Mean \pm STD & $29,833 \pm 12,108$ & $30,555 \pm 11,971$ & \\
\hline Median & 23,000 & 24,000 & \\
\hline Range & $17,00-48,00$ & $19,00-49,00$ & \\
\hline Berat badan (kg) & & & 0,250 \\
\hline$M e a n \pm S T D$ & $49,388 \pm 3,755$ & $48,000 \pm 3,325$ & \\
\hline Median & 49,500 & 48,000 & \\
\hline Range & $44,00-60,00$ & $43,00-54,00$ & \\
\hline Tinggi badan $(\mathrm{cm})$ & & & 0,425 \\
\hline$M e a n \pm S T D$ & $156,222 \pm 3,843$ & $157,111 \pm 2,654$ & \\
\hline Median & 156,500 & 157,000 & \\
\hline Range & $150,00-162,00$ & $152,00-161,00$ & \\
\hline BMI $\left(\mathrm{kg} / \mathrm{m}^{2}\right)$ & & & 0,097 \\
\hline Mean \pm STD & $20,257 \pm 1,650$ & $19,441 \pm 1,182$ & \\
\hline Median & 20,275 & 19,555 & \\
\hline Range & $17,58-23,11$ & $17,22-21,10$ & \\
\hline
\end{tabular}

Keterangan: untuk data numerik nilai p dihitung berdasar atas uji- $\mathrm{T}$ tidak berpasangan Nilai kemaknaan berdasar atas nilai $\mathrm{p}<0,05$. Tanda** menunjukkan nilai $\mathrm{p}<0,05$ artinya signifkan atau bermakna secara statistik. $* * * \mathrm{TCI}=$ Target controlled infusion, $\mathrm{BMI}=$ body mass index

\section{Pembahasan}

Data karakteristik umum subjek penelitian (Tabel 1) di antara kelompok anestesi sevofluran dan TCI tidak didapatkan perbedaan yang bermakna dalam hal usia, berat badan, tinggi badan, dan indeks massa tubuh (IMT). Hal ini menunjukkan bahwa sampel yang diambil dalam penelitian ini homogen secara statistika $(p>0,05)$ sehingga kedua kelompok layak untuk dibandingkan.

Penelitian ini menggunakan subjek penelitian yang sama, yaitu wanita dewasa (usia 18-65 tahun) yang memiliki keluhan benjolan tunggal di salah satu payudara. Faktor lain yang dapat memengaruhi efek obat adalah

Tabel 2 Perbandingan Waktu Pulih Sadar pada Kedua Kelompok Perlakuan

\begin{tabular}{|c|c|c|c|}
\hline \multirow[b]{2}{*}{$\begin{array}{l}\text { Waktu Pulih Sadar } \\
\text { (menit) }\end{array}$} & \multicolumn{2}{|c|}{ Kelompok } & \multirow[b]{2}{*}{ Nilai $\mathbf{p}^{*}$ ] } \\
\hline & $\begin{array}{c}\text { Sevofluran } \\
n=18\end{array}$ & $\begin{array}{c}\text { TCI } \\
\mathrm{n}=18\end{array}$ & \\
\hline Mean \pm STD (menit) & $7,429 \pm 0,763$ & $9,356 \pm 2,331$ & \\
\hline Median & 7,415 & 8,490 & \\
\hline Range & $6,33-8,83$ & $6,33-13,08$ & \\
\hline
\end{tabular}

Keterangan: untuk data numerik nilai p dihitung berdasar atas uji-T tidak berpasangan. Nilai kemaknaan berdasar atas nilai $\mathrm{p}<0,05$. Tanda** menunjukkan nilai $\mathrm{p}<0,05$ artinya signifkan atau bermakna secara statistik. *** TCI=target controlled infusion 
Tabel 3 Perbandingan Waktu Pemulangan Pasien pada Kedua Kelompok Perlakuan

\begin{tabular}{|c|c|c|c|}
\hline \multirow{3}{*}{ Variabel } & \multicolumn{2}{|c|}{ Kelompok } & \multirow{3}{*}{ Nilai $\mathbf{p}^{*}$ ) } \\
\hline & Sevofluran & TCI & \\
\hline & $(n=18)$ & $(n=18)$ & \\
\hline PADSS score & & & 1,000 \\
\hline Mean $\pm S T D$ & 9,444 & 9,444 & \\
\hline Median & 9,00 & 9,00 & \\
\hline Range & $9,00-10,00$ & $9,00-10,00$ & \\
\hline Waktu pemulangan (menit) & & & $0,000^{* *}$ \\
\hline Mean \pm STD & $189,05 \pm 17,20$ & $165,66 \pm 18,64$ & \\
\hline Median & 189,00 & 166,00 & \\
\hline Range & $165,00-230,00$ & $140,00-210,00$ & \\
\hline
\end{tabular}

Keterangan: untuk data numerik nilai p dihitung berdasar atas uji-T tidak berpasangan. Nilai kemaknaan berdasar atas nilai $\mathrm{p}<0,05$. Tanda** menunjukkan nilai $\mathrm{p}<0,01$ artinya sangat signifkan atau sangat bermakna secara statistik. ${ }^{* * *}$ TCI=target controlled infusion. PADSS= postanesthesia discharge scoring system

Tabel 4 Kejadian Efek Samping pada Kedua Kelompok Perlakuan

\begin{tabular}{lcc}
\hline \multirow{2}{*}{ Efek Samping } & \multicolumn{2}{c}{ Kelompok } \\
\cline { 2 - 3 } & Sevofluran & TCI \\
\cline { 2 - 3 } & $\mathbf{n = 1 8}$ & $\mathbf{n = 1 8}$ \\
\hline Pusing & 1 & 1 \\
Mual-muntah & 2 & 1 \\
Nyeri & 1 & 0 \\
Perdarahan & 0 & 0 \\
\hline
\end{tabular}

Keterangan: * TCI=target controlled infusion

indeks massa tubuh. Subjek dengan IMT yang termasuk severe overweight hingga obesitas dianjurkan untuk tidak dilakukan anestesi dengan teknik TIVA karena dapat terjadi efek paradoksal terutama karena penggunaan propofol infus.

Waktu yang dibutuhkan pasien untuk pulih sadar setelah diberikan anestesi berbeda-beda bergantung pada teknik anestesi, lama operasi, lama anestesi, dan jenis obat yang digunakan. Dari penelitian sebelumnya, penggunaan TIVA propofol, walaupun digunakan dalam waktu yang cukup panjang, menunjukkan waktu pulih sadar yang relatif cepat. Penggunaannya sebagai obat sedasi di unit perawatan intentsif menunjukkan bila digunakan selama kurang dari 48 jam kemudian dihentikan didapatkan waktu pulih sadar yang cepat. ${ }^{10}$

Pada penelitian sebelumnya, penggunaan anestesi sevofluran memberikan waktu pulih sadar yang lebih cepat dibanding dengan TIVA TCI propofol. ${ }^{9}$ Hasil penelitian ini memberikan perbandingan waktu pulih sadar teknik anestesi sevofluran yang lebih cepat dibanding dengan teknik TCI, dengan waktu pada kelompok sevofluran 7,429 $\pm 0,763$ menit, sedangkan kelompok TCI 9,356 $\pm 2,331$ menit. Hasil uji statistika memberikan nilai $p=0,022(p<0,05)$ yang berarti signifikan atau bermakna secara statistika.

Hasil penelitian ini menunjukan bahwa waktu pulih sadar pada kelompok sevofluran lebih cepat bila dibanding dengan kelompok TCI. Kondisi tersebut dapat disebabkan oleh sifat gas sevofluran (temperature-dependent decomposition) yang akan terurai saat kontak dengan $\mathrm{CO}_{2}$ absorbent (soda lime dan bara lime). Pada suhu $80^{\circ} \mathrm{C}$, sevofluran dengan cepat mengalami dekomposisi dengan kecepatan $92 \%$ perjam. Hexafluoroisopropanol,metabolit utama sevofluran, berkonjugasi secara cepat dengan senyawa inert. Karena eliminasi yang cepat, ikatan kovalen terhadap makromolekul hepar cenderung tidak terjadi. Kelarutan yang rendah di dalam darah menyebabkan cepatnya terjadi ekuilibrium tekanan inspirasi 
parsial di alveoli. Hal ini pula yang membuat eliminasinya menjadi lebih cepat. Waktu pulih sadar yang cepat pada penggunaan anestesi sevofluran juga dapat disebabkan oleh gas/ volatil yang dihirup melalui pernapasan, dan pada saat aliran gas dihentikan, gas yang masih berada dalam tubuh dapat dikeluarkan melalui proses pernapasan sehingga kadar gas dalam tubuh makin lama makin berkurang sampai pasien bangun. Penggunaan sevofluran untuk pemeliharaan anestesi, pasien akan bangun lebih cepat setelah gas dihentikan dan hemodinamik juga lebih stabil. ${ }^{4,5}$

Pemulihan adalah suatu proses yang secara tradisional dibagi atas 3 bagian yang saling tumpang tindih, yaitu early recovery (fase $1)$, intermediate recovery (fase 2), dan late recovery (fase 3). Early recovery dimulai dari dihentikannya obat anestesi supaya pasien bangun, kembalinya refleks proteksi jalan napas dan dimulainya aktivitas motorik, fase ini biasanya terjadi di Postanesthesia Care Unit (PACU). Intermediate recovery bila sudah mencapai kriteria untuk dapat dipulangkan ke rumah dan late recovery dari mulai dipulangkan sampai pulihnya fungsi fisiologis ke keadaan seperti sebelum pembedahan. ${ }^{3,18}$

Pada early recovery dilakukan pemantauan dengan sistem skoring modifikasi Aldrete yang bila sudah mencapai $\geq 9$ boleh dipindahkan ke ruang pulih fase $2 .^{1,3,19}$ Di ruang pulih fase 2 , pasien dipantau dengan menggunakan sistem skoring PADSS yang bila sudah mencapai $\geq 9$ pasien boleh dipulangkan., ${ }^{3,19}$

Hasil penelitian ini menunjukan bahwa waktu pemulangan pada kelompok sevofluran $189,05 \pm 17,20$ menit, sedangkan kelompok TCI $165,66 \pm 18,64$ menit dengan perbedaan yang sangat signifikan atau sangat bermakna secara statistika $(\mathrm{p}<0,01)$. Hal ini dapat disebabkan oleh efek samping pada kelompok anestesi sevofluran lebih banyak (pusing, mual-muntah, dan nyeri) sehingga dapat memperpanjang waktu pemulangan.

Semua pasien rawat jalan dapat pulang ke rumah bila memenuhi kriteria pemulangan pasien berdasar atas kriteria PADSS dengan skor $\geq 9$. Secara umum dapat dinilai, kembalinya fungsi kognitif secara penuh, tanda vital yang semakin stabil, nyeri dan mual-muntah yang terkendali dengan baik, serta fungsi motorik yang semakin sempurna. ${ }^{3,18,19}$

\section{Simpulan}

Berdasar atas hasil penelitian dan pembahasan, dapat disimpulkan bahwa teknik anestesi dengan menggunakan agen inhalasi sevofluran menunjukkan waktu pulih sadar yg lebih cepat dibanding dengan teknik TIVA TCI propofol. Teknik TIVA TCI propofol menunjukan waktu pemulangan pasien yg lebih cepat dibanding dengan teknik anestesi sevofluran. Sistem PADDS untuk kriteria pemulangan pasien pada teknik TIVA TCI propofol menunjukkan waktu yang lebih cepat tercapai dibanding dengan teknik anestesi menggunakan agen inhalasi sevofluran, dikarenakan pada teknik TCI propofol efek samping yang minimal saat berada di ruang pemulihan.

\section{Daftar Pustaka}

1. Burke B, Kyker M. Speeds criteria vs modified aldrete and fast-track criteria for evaluating recovery in outpatient. Open J Anesth. 2013;3:309-14.

2. White PF, Kehlet $\mathrm{H}$. The role of the anesthesiology in fast-track surgery: from multimodal analgesia to perioperative medical care. Anesth Analg. 2007;104:1380-96.

3. Bisri T, penyunting. Ambulatory anesthesia. Bandung: Saga Olahcitra; 2007.

4. Ebert TJ. Inhalational anesthesia. Dalam: Barash PG, Cullen BF, Stoelting RK, penyunting. Clinical anesthesia. Edisi ke-5. Philadelphia: Lippincott; 2006. hlm. 384420.

5. Morgan GE, Mikhail MS, Murray MJ. Clinical anesthesiology. Edisi ke-5. New York: McGraw Hill,Inc; 2013.

6. Brunton LL, Parker KL. Inhalational anesthetics. Dalam: Lazo JS, penyunting. Goodman \& Gilman's, Manual of pharmacology and therapeutics. Edisi ke11. McGraw Hill,Inc; 2008. hlm. 232-9.

7. Liu SS, Strodtbeck WM, Richman JM, Wu CL. 
A comparison of regional versus general anesthesia for ambulatory anesthesia: a meta-analysis of randomized controlled trials. Anesth Analg. 2005;101(6):163642.

8. Buchh V, Saleem B, Reshi F, AM H, Gurcoo S, Shora A. A comparison of total intravenous anesthesia (TIVA) to conventional general anesthesia for day care surgery. Internet J Anesthesiol. 2009;22(1):1-6.

9. White PF, Romero G. Intravenous anesthetics. Dalam: Barash PG, Cullen $\mathrm{BF}$, Stoelting RK, penyunting. Clinical anesthesia. Edisi ke-6. Philadelphia: Lippincott Williams \& Wilkins; 2009. hlm. 451-3.

10. White PF. Propofol: its role in changing the practice of anesthesia. Anaesthesiology. 2008;109(6):1132-6.

11. Schraag S, Kreuer S, Bruhn J, Frenkel C, Albrecht S. [target-controlled infusion (TCI) - a concept with a future?: stateof-the-art, treatment recommendations and a look into the future]. Anaesthesia. 2008;57(3):223-30.

12. Reves JG. Nonvolatile anesthetic agent. Dalam: Morgan GE, Mikhail MS, Murray MJ, penyunting. Clinical anesthesiology. Edisi ke-4. New York: McGraw-Hill Companies,Inc; 2006. hlm. 200-2.

13. Absalom AR, Mani V, Smet TD, Struys MM. Pharmacokinetic models for propofol=defining and illuminating the devil in the detail. Br J Anaesth. 2009;103(1):26-37.

14. Cerrato F, Labow BI. Diagnosis and management of fibroadenomas in the adolescent breast. Semin Plastic Surg. 2013;27(1):23-5.

15. Lichtor J, Kalghatgi S. Outpatient anesthesia. Dalam: Longnecker D, Brown D, Newman M, Zapol W, penyunting. Anesthesiology. Edisi ke-2. New York: McGraw-Hill Companies,Inc; 2008. hlm. 1608-24.

16. Urban B. The site of anesthetic action. Dalam: Schuttler J, Schwilden H, penyunting. Modern anesthetics. Volume 182. Heidelberg: Springer; 2008. hlm. 1-5.

17. Bruhn J, Myles PS, Sneyd R, Struys M. Depth of anesthesia monitoring: what's available, what's validated and what's next? Br J Anaesth. 2006;97(1):85-94.

18. Kaswiyan, U, penyunting. Anestesi pada bedah rawat jalan. Bandung: Departemen anestesiologi dan terapi intensif, Fakultas Kedokteran Unpad/RSUP Dr. Hasan Sadikin; 2014.

19. Butterworth J, Mackey DC, Wasnick J. Dalam: Morgan GE, Mikhail MS, Murray MJ, penyunting. Postanesthesia care. Clinical anesthesiology. Edisi ke-5. New York: Mc Graw Hill; 2013. hlm. 1257-75. 